\title{
SOBRE GÓNGORA Y EL GONGORISMO COLONIAL
}

Por

JOHN BEVERLEY

University of Pittsburgh

"Pondérase la discordancia", escribe Gracián en su Agudeza y arte de ingenio, "y luego pasa el ingenio a dar sutil y adecuada solución." El arte de ingenio se aprende en el laboratorio del concepto poético, pero se aplica en el ejercicio del poder político donde el "varón avisado" tendrá que navegar por el laberinto de la Corte. En el soliloquio del peregrino, en la Soledad segunda, Góngora se representa como Ícaro-_aquel que con las alas derretidas / cayendo fama y nombre al mar ha dado" (Garcilaso, soneto 12):
Audaz mi pensamiento
el cenit escaló, plumas vestido,
cuyo vuelo atrevido,
si no ha dado su nombre a tus espumas,
de sus vestidas plumas
conservarán el desvanecimiento
los anales diáfanos del viento.

El acto de ingenio como una forma de cálculo existencial en un "mundo trabucado"-un "vuelo"-, o como un "desvanecimiento", un deshacerse: ésto, son los polos de la imaginación barroca. El vuelo de f́caro funciona aquí como una alegoría metonímica de la escritura ("pensamiento... plumas vestido").

A la didáctica medieval y renacentista sirvió como ejemplo de los límites propios al conocimiento humano; emblematiza la doctrina de noli altum sapere-no atreverse a conocer las cosas "altas". Pero Góngora tendrá en cuenta aquí el sentido de Ícaro, muy difundido en el siglo XVII, como arquetipo positivo del que se atreve peligrosamente a revelar arcana naturae-los secretos de la naturaleza. Como señala Carlo Ginsburg: "Las ideas mismas de 'peligro' y 'novedad' comienzan a ser vistas como valores positivos en una sociedad fundada más y más sobre el comercio. Nil linguere inausam (atreverse a todo) reemplaza el noli altum sapere escolástico." "Este nuevo fcaro barroco no es solamente el poeta o el intelectual: representa también (como la situación del mismo peregrino de

1. Carlo Ginsburg: "High and Low: The Theme of Forbidden Knowledge", Past and Present, 73 (1977), p. 38. Traducción mía del inglés. 
las Soledades) al cortesano-el "político" de Gracián, jugando su destino entre la sublimación y el desastre. En una anécdota más utilitaria pero no menos reveladora, Emilio Carilla observa en su ensayo sobre el gongorismo colonial;

En Lima, el Real Colegio de San Martín..., en alabanza al virrey por la construcción de un muelle, le ofrece "una varia y hermosa y florida selva de poesías", que no es precisamente varia, hermosa, ni florida, aunque sí, con frecuencia, gongorista. ${ }^{2}$

Nos proponemos aquí hacer un bosquejo de la relación entre el gongorismo como un fenómeno estético y la estructura del poder colonial de España en la primera mitad del siglo XVII, época de crisis y consolidación de su imperio americano. ¿Relación de disidencia o de conformidad? Podemos notar, para comenzar, la existencia de una polémica reciente sobre este punto y sobre el valor del llamado "neobarroco" en las letras latinoamericanas. Según Severo Sarduy, el barroco (y, en el terreno del discurso, más particularmente el gongorismo) configura, en principio o en potencia, una práctica subversiva del orden establecido.

Ser barroco hoy significa amenazar, juzgar y parodiar la economía burguesa, basada en la administración tacaña de los bienes, en su centro y fundamento mismo: el espacio de los signos, el lenguaje, soporte simbólico de la sociedad, garantía de su funcionamiento, de su comunicación. . . El barroco subvierte el orden supuestamente normal de las cosas, como la elipse-ese suplemento de valor-subvierte y deforma el trazo, que la tradición idealista supone perfecto entre todos, del círculo. ${ }^{3}$

De allí su conocida consigna "barroco de la revolución" y su celebración del barroco "estridente, abigarrado y caótico" de Lezama Lima como modelo de un discurso de liberación. ${ }^{4}$

Leonardo Acosta responde que, al contrario,

El barroco fue un estilo importado por la monarquía española como parte de una cultura estrechamente ligada a su ideología imperialista. Su importación tuvo, desde el principio, fines de dominio en el terreno ideológico y cultural. Esto no implica una valoración estética negativa. Pero sí estimamos necesaria una toma de conciencia respecto a la verdadera significación del barroco, que es un fenómeno estrictamente europeo, y al imperativo de elaborar nuestras propias formas artísticas en la etapa de liberación económica, política y cultural de la América Latina, formas que en una serie de aspectos serán todo lo contrario del barroco. 5

2. Emilio Carilla: El gongorismo en América (Buenos Aires, 1946), p. 231.

3. Severo Sarduy: Barroco (Buenos Aires, 1974), p. 99. Ver también su ensayo "Barroco y neobarroco", en América Latina en su literatura (México, 1973).

4. Sarduy: Barroco, p. 104.

5. Leonardo Acosta: "El 'barroco americano' y la ideología colonialista", Revista Unión (La Habana), XI, nos. 2-3 (1972), p. 59. 
Jaime Concha hace eco de esto cuando observa que "la renovación gongorina ...se pone al servicio de intenciones claramente apologéticas del orden colonial, especialmente de una superestructura administrativa y eclesiástica." 6

Lo específico del gongorismo como manera poética, lo que define su novedad, su "vuelo atrevido", es, sin duda, su cultivo de una dificultad formal rebuscada. La defensa de la dificultad como una cualidad estética en sí fue hecha antes de Góngora por los manieristas italianos en conexión con una defensa neoplatónica de la libertad de creación artística. ${ }^{7}$ Por otra parte, la poética aristotélica de la Contrareforma, con su conocido énfasis en la disciplina de las reglas y en la subordinación necesaria del efecto estético a la didáctica, sostenía que el gongorismo manifestaba una desvinculación de la relación escolástica verba y res-el lenguaje y lo que significaba. Por haber elevado el juego lingüístico ingenioso como centro del gusto poético, no directamente relacionado con la moral o la doctrina, se pensaba que Góngora había producido un formalismo funcionalmente ateo, que su poesía era babélica. De allí los ataques a él como supuesto converso (Quevedo) o, en palabra del humanista Francisco Cascales, "Mahoma de la poesía española." 8

Góngora se defendió de estos ataques en una carta abierta de 1615, la llamada "Carta en respuesta." Su argumento central es el siguiente:

...en dos maneras considero me ha sido honrosa esta poesía [de las Soledades y el Polifemo]; si entendida por los doctos, causarme ha autoridad, siendo lance forzoso venerar que nuestra lengua a costa de mi trabajo haya llegado a la perfección y alteza de la latina... . ¿y qué razón della no está corriente en lenguaje heroico, que ha de ser diferente de la prosa y digno de personas capaces de entenderle? Demás que honra me ha causado hacerme escuro a los ignorantes, que esa es la distinción de los hombres doctos, hablar de manera que a ellos les parezca griego; pues no se han de dar las piedras preciosas a animales de cerda. ${ }^{9}$

6. Jaime Concha: "La literatura colonial hispano-americana: problemas e hipótesis", Neohelicon (Budapest), IV, nos. 1-2, p. 46.

7. Ver el famoso estudio de Erwin Panofsky: Idea: A Concept in Art Theory (publicado nuevamente en inglés por la University of Missouri Press, 1968), y Andrée Collard: Nueva poesía: conceptismo, culteranismo en la crítica española (Madrid, 1967).

8. Francisco Cascales: Cartas filológicas (Madrid, 1959), II, p. 188. A esto se debe la recepción paradójica del gongorismo en la España de la Decadencia. Por un lado, la venta de la primera edición comercial de su poesía, las Obras en verso del Homero español recopiladas por López de Vicuña después de la muerte del poeta, es prohibida por varios años por la Inquisición; por otro, el Conde Duque de Olivares, nuevamente instalado como favorito del rey, comisiona una edición caligrafiada sobre vitela para su biblioteca particular (el llamado manuscrito Chacón).

9. Cito la versión de la "Carta en respuesta" en Ana Martínez Arancón: La batalla en torno a Góngora (selección de textos) (Barcelona, 1978). 
Hay que subrayar varias cosas aquí. Primero, la idea de que la poesía "causa"-dicho de otro modo, significa-honor; es decir, que se relaciona con el problema de sublimación estamental. Segundo, la idea de la poesía como un trabajo (“... a costa de mi trabajo"), lo que Espinosa Medrano más tarde denominaría una "fabricación." 10 Tercero, la visión del latín clásico, como lenguaje paradigmático. Cuarto, la suposición de que el gongorismo representa una forma de "lenguaje heroico" apropiado a sujetos épicos o trágicos. Quinto, que, por lo tanto, requiere dificultad en la construcción y en el léxico para ser digno de los que puedan entenderlo, es decir, de los que son "doctos", que poseen honor, que son los protagonistas legítimos de acciones épicas o trágicas: en una palabra, la aristocracia. El español vulgar-lo que Góngora llama "el romance" en su carta-es visto como un lenguaje que tiene que ser instrumentalizado porque en su estado natural carece de la "perfección y alteza de la latina", no es digno de su sujeto. El trabajo del poeta es haber extendido y sublimado su capacidad significativa. "El romance" adquiere así, en el artefacto poético, la condición de un lenguaje imperial: ordenador, monumentalizador, universalizador, y esto "causarme ha autoridad". Bajo la rúbrica de un común arte de ingenio aristocrático se equipara aquí tácitamente el dominio del discurso escrito-función que la división del trabajo concede a las técnicas especializadas del poeta-con el dominio de gobierno y economía. El poeta es vate: legislador de la conciencia de una clase dominante. La dificultad de su discurso-_"hablar de manera que a ellos les parezca griego"-asegura que el vulgo deshonrado (o el que posee un falso título de honor: la noblesse du robe) no pueda hacerlo suyo. Es un discurso, insiste Góngora, "no para los muchos", destinado a evitar el estado de una mercancía que podría ser comprada y consumida por cualquiera, a circular solamente en manuscrito entre las tertulias de la corte. (A pesar de su situación económica a menudo precaria, Góngora rehusó siempre la posibilidad de publicar su obra poética durante su vida.)

¿Quienes eran estos "hombres doctos" que producían y/o consumían el gongorismo en el siglo XVII? Con referencia particular a la Colonia, Jaime Concha opina que "es fructífero ver en el gongorismo un primitivo momento de constitución de una ideología de las capas medias del Virreinato en su grupo de letrados..., la consolidación de una cierta conciencia de élite cultural debido a manejar un instrumento técnico complejo como es la poesía gongorina." ${ }^{11} \mathrm{El}$ absolutismo español dió 10. Ver Eduardo Hopkins: "Poética de Espinosa Medrano en el Apologético en favor de $D$. Luis de Góngora", Revista de crítica literaria latinoamericana (Lima), IV, nos. 7-8, pp. 105118; y Alfredo Roggiano, "Juan de Espinosa Medrano: Apertura hacia un espacio crítico en las letras de la América Latina", en Raquel Chang-Rodriguez, Prosa Hispanoamericana Virreinal (Barcelona, 1978), pp. 101-111.

11. Concha: "La literatura colonial", p. 45. 
lugar, como en otras partes de Europa, a la marginación y disminución relativa de amplios sectores de la aristocracia tradicional. Como los estamentos feudales continuaban en vigor durante el siglo de oro, una posición de "alteza" socio-política requería, nominalmente por lo menos, un título. El historiador José Antonio Maravall ha mostrado, por ejemplo, que la prueba de pureza de sangre se empleaba no sólo para discriminar en los nombramientos oficiales contra los conversos, sino también contra los que no tenían sangre noble. ${ }^{12}$ Pero, por otro lado, un título por sí mismo podía significar poco en una sociedad dominada por actividades empresariales, por un mercado de bienes nacional e internacional y por la circulación general del dinero. El caso del escudero en el Lazarillo que ha perdido su hacienda y vive en la más absoluta miseria sirve para precisar que existe una discontinuidad posible entre el honor como atributo estamental y su base económica en las diversas formas de renta feudal. La situación social de muchos hidalgos quedaba, así, sujeta a una doble y a veces contradictoria determinación. El concepto de calidad y autoridad como atributos naturales de nobleza de sangre tiende a ser mediatizada por una competencia general y abierta-análoga al "medro" plebeyo de la novela picaresca-, y el requisito de una especialización técnica para conseguir un oficio en el enmarañado aparato burocrático y eclesiástico. El hidalgo del barroco tiene que ser "limado" para pasar de una situación marginal a los centros de poder y riqueza. Depende del patronaje de los grandes.

Esta modificación interna de la aristocracia explica en parte la función y el crecimiento enorme - van de 5 en tiempos de los Reyes Católicos a más de 20 en época de Góngora-de las universidades españolas y coloniales durante el siglo de oro. (Richard Kagan observa: "since students stemmed largely from the nobility, particularly de numerous hidalgo class which may have constituted up to one tenth of Castile's population, perhaps as many as one quarter or one third of Castile's young noblemen may have received some form of university or university-level education." ${ }^{13}$ ) El producto de este sistema de educación superior, el letrado, viene a ser en el siglo XVII el intelectual orgánico del imperialismo español. Ahora bien, ser letrado significaba dominar y saber manejar una de las diferenciadas pero entrelazadas prácticas intelectuales que formaban, en conjunto, la base del

12. Ver, por ejemplo, José Antonio Maravall: "La función del honor en la sociedad tradicional", Ideologies and Literature (University of Minnesota), II, no. 7 (1978), pp. 9-27, y su La cultura del barroco (Barcelona, 1975). La relación de Góngora con una pequeña aristocracia provinciana amenazada por la economía política del absolutismo hapsburgo es expuesta por Robert Jammes en su monumental biografía del poeta: Études sur l'oeuvre poétique de D. Luis de Góngora (Burdeos, 1967).

13. Richard Kagan: "Universities in Castille; 1500-1700", Past and Present, no. 49 (1971), p. 49. 
mantenimiento y la reproducción de la hegemonía aristocrática tanto en España como en la Colonia. Pero todas estas prácticas (jurisprudencia, teología, etc.) tenían en común la necesidad de ser elaboradas en un discurso escrito estilísticamente compatible con los presupuestos de una "elevación" nobiliaria. De allí que Góngora insiste en que su poesía requiere un trabajo especifico en su composición e interpretación y que en esto consiste su utilidad. Su cultivo de la dificultad significa una sublimación estamental por parte del emisor y receptor a la vez, una autoridad. Frente a la amenaza de una naciente cultura burguesa, la poética del gongorismo implica una especie de fetiche aristocrático de una forma extremadamente elaborada, vista como noble o sublime porque elude la comprensión del vulgo y se sitúa fuera de la órbita del mercado y del dinero como rnedio de cambio y posesión. ${ }^{14}$

Lo que transmite el gongorismo no es sólo un signo de ascendencia social sino también una técnica de poder social, un instrumento de legitimación y dominación. El discurso es un ejercicio que, por su dificultad, agudiza y habilita la inteligencia del poder. ${ }^{15}$ Se dirige a una clientela de patrones-los grandes-en los centros de acumulación y legislación del imperio: la Corte, los Virreinatos, la red de ciudades.

14. Hay, por supuestc, una ambigüedad en la carta de Góngora: ies que una aristocracia de letras (es decir, de "hombres doctos") sería equivalente a una aristocracia de sangre, ya que la división entre trabajo manual e intelectual no correspondía necesariamente a la división estamental entre la nobleza y el vulgo en época de Góngora? Aunque los letrados hablan en nombre de y por la gran nobleza, no son parte de ella, como hemos observado. "¿Se puede ser letrado sin ser noble?", pregunta Jaime Concha. Continúa:

Ya muy entrado el siglo XVII el letrado seguía siendo un ser indefinible, es decir, huérfano de una clara definición social... Ser noble, ser sacerdote, ser ganapán, eran cosas muy nítidas, aristotélica y escolásticamente nítidas en la conciencia colectiva del período. No así el letrado, cuya práctica social no encajaba plenamente dentro de la mentalidad excluyentemente nobiliaria de los estamentos dominantes... ¿Constituye la actividad de las letras, sobre todo de las letras profanas relacionadas directamente con el derecho y la jurisprudencia, una sabiduría autónoma que se justifique a sí misma? En el tiempo, las reacciones a estas preguntas oscilan en un abanico de posibilidades que va desde la básica postulación del letrado-noble, hasta un débil conato ideológico de reconocer la especificidad técnica de tal praxis intelectual.

(En "Introducción al teatro de Ruiz de Alarcón", Ideologies and Literature, II, no. 9 (1980). La insistencia de Góngora en el trabajo que exige su poesía representa una variante de esta problemática. En el pensamiento tradicional uno o es noble o no lo es. ¿Porque haría falta un "trabajo"-palabra que había adquirido en el siglo XVI una connotación peyorativa y plebeya-para significar la nobleza de uno? Pero Góngora también tendrá en cuenta el sentido más antiguo de trabajo como prueba de virtud y valor (Cf. Cervantes: Los trabajos de Persiles y Segismunda).

15. En su carta, Góngora explica que "si la obscuridad y estilo intrincado de Ovidio... da causa a que, vacilando el entendimiento en fuerza del discurso, trabajándole (pues crece con cualquier acto de valor), alcance lo que así en la lectura superficial de sus versos no pudo entender, luego hase de confesar que tiene utilidad avivar el ingenio, y eso nació de la obscuridad del poeta". (Cursivas mías) Lectura como "acto de valor": posición que se remite a la problemática sobre la función social del letrado indicada en la nota anterior. 
Propone una manera de ritualización y pseudo-universalización de estos centros: un lenguaje heroico. Crea entre poeta y príncipe y contra "los muchos" (es decir, en el caso de la Colonia, contra la población indígena) una comunidad lingüística diferenciadora. Por lo tanto, es un modo de inserción y de medro para el hidalgo dentro del aprato ideológicoburocrático del imperio, como demuestran las "justas poéticas" de los Virreinatos.

Esto nos lleva a un segundo punto: la cuestión de la temática del gongorismo y, en particular, su representación de la dialéctica de ciudad y campo.

Como hemos visto, Góngora se jacta de haber creado un lenguaje heroico. Ahora bien, la disciplina aristotélica de las reglas permitía a la poesía épica o trágica una complicación extraordinaria de sintaxis y lexis para que el estilo de imitación correspondiese a la supuesta complejidad y universalidad de su materia. Pero la poesía gongorina no tiene una temática épica; es más bien una especie de bucólica cortesana. Para la crítica anti-gongorina del siglo XVII, su pretensión estética fallaba no sólo por su formalismo, su falta de relación directa con la didáctica, sino también porque significaba una idealización de-en palabra de Jáuregui - cosas humildes", produciendo asi un "desgarrón afectivo", un desdoblamiento entre significante y significado. ${ }^{16}$

Esta anomalía, sin embargo, explica en parte por qué el gongorismo se extendió como un discurso estético quasi-oficial en España, Portugal y la Colonia en los años después de la muerte de Góngora. El período expansionista del imperialismo español-la Conquista-había sido completado hacia finales del siglo XVI. Bajo la presión externa de Inglaterra, Francia y los Países Bajos, e interna del desastre económico y demográfico ocasionado por la explotación de la población indígena en la producción de oro y plata, la Colonia entra en proceso de contracción y reestructuración. El problema de los privados como Lerma y Olivares y de los Virreinatos americanos era ya no tanto extender sino mantener la unidad y el orden de un laberíntico imperio, preservando el monopolio mercantil de la metrópoli española y la estructura del poder nobiliario en las relaciones de producción. Esto requería una estrategia de zorro en vez de león, el discreto gracianesco en vez de su héroe. Entre otras cosas, era preciso desarrollar un estado civil colonial en el que la función de las letras-jurisprudencia, pedagogía, discurso político-moral, belles lettres, religiosidad, etc.-escondiera y aminorara la necesidad de gobernar a

16. Juan de Jáuregui: Antídoto contra la pestilente poesía de las SOLEDADES (1614). Texto en Eunice J. Gates, Documentos gongorinos (México, 1960), p. 86. Cascales observó de la manera poética de Góngora: "Ella no es buena para poema heroico, ni lírico, ni trágico, ni cómico: luego es inútil”. Cartas, p. 186. 
través de un monopolio de los medios de violencia. Ahora el discurso paradigmático de las armas es la épica. Pero la épica como género poético había perdido su vigor en el contexto de la decadencia imperial del siglo XVII: representaba una forma de heroísmo-el telos de la voluntad bélica-ya anacrónica. Si las acciones del héroe épico tienen por eje la dualidad entendimiento-voluntad, las del hombre de la "nueva política" de la Corte barroca-el privado-tienen por eje la dualidad genio-ingenio. Es aquí donde surge la heterodoxia del ejercicio que propone el gongorismo: dar una estilización épica a materias no épicas, construir una poesía bucólica pero intelectualizada que sería "émula de las trompas", como suele declarar Góngora en sus dedicatorias. El gongorismo preservaba el alcance y la sublimidad de la épica-su función de legitimizar e idealizar el proyecto histórico de una clase dominante-pero en una situación (el mundo del Quijote) en que la poetización de una expedición militar ya tendría un sabor arqueológico, como algo pasado de moda. Las Soledades, el Polifemo, el hoy menos conocido Panegírico al Duque de Lerma, ofrecían al letrado colonial modelos de un nuevo género post-épico en que las actividades ordinarias de la producción, acumulación y reproducción social-es decir, la sociedad civil colonial y su estructura de poder-podían ser perfiladas e idealizadas.

Es importante ver, en este sentido, que el manejo del tópico de menosprecio de corte y alabanza de aldea-cliché de la temática gongorina - representa en el gongorismo colonial sólo una contradicción nominal, en la que la contradicción verdadera-la explotación del campo por la ciudad, de la población indígena por una aristocracia colonizadora, de la periferia por la metrópolis-queda mistificada. Si la épica renancentista ha perdido su vigor, también el "lugar ameno" pastoril ha perdido su sentido como contra-utopía, refugio del alma noble, ante las devastaciones de la historia y del poder. Crear un lenguaje heroico para representar temas bucólicos equivale a diacronizar lo pastoril, abrirlo a la historia, someterlo a una voluntad extrínseca. El sabor campesino y bucólico de la poesía gongorina deriva necesariamente de una falsificación idealizadora de los datos reales de vida y producción en el campo español o colonial. ${ }^{17}$ Obedece, en su procedimiento técnico-metafórico, a la misma estructura de explotación y acumulación que caracteriza el mercantilismo feudal. Lo rural, lo indígena, no es válido en sí. Tiene que ser pulido y limado, puesto en relación con una lógica supuestamente universalizadora y ordenadora propia a una aristocracia urbanizada e imperialista y al espectáculo de esa concentración de poder y riqueza que es la ciudad-corte

17. Robert Jammes precisa "qu'en présentant le idéal de vie rustique Góngora ne prétend pas évoquer la masse des paysans dans son ensemble, mais seulment les plus riches d'entre eux". Études, p. 617, nota 87 . 


\section{del absolutismo barroco. ${ }^{18}$ En su análisis de las comedias de Calderón, Walter Benjamin observó acertadamente:}

Lo que es decisivo en el escapismo pastoril del barroco no es una antítesis entre historia y naturaleza; representa más bien la secularización de lo histórico en el estado de la naturaleza. La comedia española incluye el panorama de toda la naturaleza, pero vista como sujeta a la Corona. . . Por otro lado, el orden social y su representación, la Corte, son vistos como un fenómeno natural del más alto orden, cuya primera ley es el honor del príncipe. . . 19

Lo que caracteriza la poesía colonial americana es la manera en que el gongorismo es utilizado para mistificar a través de su poderosa alquimia estilística y metafórica las bases reales de la riqueza y los bienes de consumo en el trabajo de las masas indígenas. Esto es parte de su servicio como práctica ideológica a la clase dominante. Un caso ejemplar es ese festival del fetichismo de la mercancía, La grandeza mexicana de Bernardo

18. Recordemos que el barroco, como estilo, corresponde a una época de conquista del campo por la ciudad:

Era uno de los grandes triunfos del barroco organizar el espacio, darle continuidad, medirlo y ordenarlo, extender los limites de su magnitud, combinando igualmente lo extremamente distante y lo extremamente diminuto; finalmente, asociar el espacio y la moción... La centralización de poder en la capital política fue acompañada por una pérdida de iniciativa y poder en los centros regionales... La ley, el orden, la uniformidad son los productos específicos de la capital barroca; pero la ley existe para confirmar los estamentos y posición de las clases dominantes, y el orden es un orden mecánico. La manera externa de mantener esta forma de vida es el ejército; su brazo económico es el mercantilismo; y sus instituciones más típicas son el ejército, la bolsa, la burocracia, y la Corte. Existe una harmonía subyacente entre todas estas instituciones; en conjunto constituyen una nueva forma de vida social: la ciudad barroca.(Lewis Mumford: The Culture of the Cities (New York, 1939), p. 30. Traducción mía del inglés.

19. Walter Benjamin: Ursprung der deutschen Trauerspiels (1925) (El origen de la tragedia alemana), en su Gessamlte Schriften, t. I (Frankfurt, 1974). Traducción mía del alemán. Noèl Salomon demostró que el proceso de legitimización ideológica en la comedia del siglo de oro implicaba para el principe un período necesario de aprendizaje en el campo. Como aristócrata, se ha urbanizado: es un hombre de la corte y no de la hacienda, el núcleo productivo y social del sistema feudal. El laberinto arquitectónico, político y moral de la ciudad le esconde las "eternas verdades" de la vida rústica. Tiene que dejar (o ser exilado de) la ciudad, disfrazarse como villano, hacerse "uno de ellos". Recherches sur le thème paysan dans le 'comedia' au temps de Lope de Vega (Burdeos, 1967). Es precisamente la situación del personaje típico del gongorismo-el peregrino andante, "náufrago y desdeñado, sobre ausente". Pero el destino del héroe no es quedarse en el exilio o el ocio pastoril, en la "soledad confusa" del estado de la naturaleza y de comunidades humanas igualitarias y candorosas. Tiene que volver a la Corte, reconciliarse con la "enemiga amada" que ha provocado su exilio, hacerse gobernador. Lo que Benjamin llama la "dialéctica de escena" en la representación barroca del proceso histórico, es un esfuerzo de presenciar y, a la vez, de reconciliar ideológicamente (es decir, a través de la producción en el artefacto estético de una conciencia falsa) una serie de oposiciones inquietantes: naturaleza/cultura, ciudad/campo, centro/periferia, historia(cambio)/orden estamental "eterno", pueblo/estado, cultura metropolitana/cultura plebeya o indígena, virtud/poder, entendimiento/voluntad, etc. Al centro de todos ellos - su punto de irradiación-el conflicto irremediable en un sistema basado en relaciones de producción feudales entre campesino y noble. 
de Balbuena, donde los bienes materiales que ofrece "la primavera mexicana" a los colonizadores son "regalos"-como en el mito de la Edad de Oro-y, por lo tanto, la figura del "feo indio"-fuente real de esta riqueza-queda necesariamente ausente de la representación hasta los versos finales. ${ }^{20}$ En la metáfora gongorina, la riqueza y el poder aparecen como reflejos automáticos de una providencia teleológica, y no como productos de una elaboración humana realizada bajo determinadas relaciones de producción y acumulación explotadoras. Las Soledades o el Polifemo presentan a la naturaleza como una gran máquina productora de gente y de bienes-el tópico barroco de la cornucopia-, todos a servicio y a la disposición de un protagonista noble/peregrino. Beatrice Pita nos ofrece los siguientes ejemplos de las Soledades (se podrían multiplicar fácilmente):

- "le dió el robre alimento" (I, 142)

_.orladas sus orillas...cornucopia" $(\mathrm{I}, 200)$

_."le rindió [el Perú]...blancas hijas... metales" $(I, 431)$

— "te guardan su más precioso engaste" $(I, 446)$

- "expriman líquido a Minerva" (I, 827)

- “dió la ría pescados" (II,104)

- "la sierra dió bacantes" (I, 272)

- “cuantos la sierra dió, cuantos dió el llano"( $(1,854)$

- "la vista saltearon poco menos las no líquidas perlas" (muchachas) (II, 230)

- "tanta ofrecen los álamos zagala" $(I, 664)$

- "tres hijas suyas candidas le ofrecen" (II, 218)

- "libremente corresponde a los pescadores la pesca" (II,82)

- “del arbol que ofreció a la edad primera" (II, 341)

"Es a una 'divina próvida mano' (II, 362) a quien se deben los bienes", concluye ella. "Todo dentro del idealizado, pero caduco, mundo de las Soledades refeja esta misma visión teleológica de las personas, las relaciones, el propósito y la utilidad de las cosas: la naturaleza da los bienes de la tierra, los serranos/pescadores están allí, y es el noble quien da un sentido y un orden al conjunto". ${ }^{21}$ Es así como la famosa decoración metafórica de Góngora se vuelve en el gongorismo colonial una especie de

20.

$$
\begin{aligned}
& \text { Y pues ya al cetro general te ensayas } \\
& \text { con que dichosamente el cielo ordena } \\
& \text { que en triunfal carro de oro por él vayas, } \\
& \text { entre el menudo aljófar que a su arena } \\
& \text { y a tu gusto entresac el indio feo, } \\
& \text { y por tríbuto dél tus flotas llena. } \\
& \text { (La grandeza mexicana, epílogo.) }
\end{aligned}
$$

21. Beatrice Pita: en una investigación realizada para mi seminario sobre el gongorismo en el Departamento de Literatura, University of California, San Diego (1980, sin publicar). 
teoría de acumulación mágica que enmascara la real "primitiva acumulación de capital" (para emplear la frase de Marx), armonizándola, en apariencia, con los presupuestos religiosos, aristocráticos y metropolitanos de la ideología imperial española: discurso-espejo que permite al colonizador el lujo de pensar que su situación de privilegio y poder es un fenómeno "natural" y providencial, que habita un espacio social en principio armónico y utópico, en que toda rebelión o disidencia se descalificaría automáticamente como producto de fuerzas del mal que amenazan "desconstruir" este orden.

A la pregunta de cómo el gongorismo, atacado y censurado como heteredoxo en España durante la vida de Góngora, llega paradójicamente a ser el discurso estético oficializante de la Colonia en su período de crisis y consolidación, podemos entonces responder: Representa, en esencia, una nueva modalidad de colonización (por las letras en vez de por las armas, aunque por supuesto, éstas quedan "en reserva"). Es una técnica, un arte de ingenio, un ejercicio que puede servir como forma de adoctrinamiento en las nuevas prácticas ideológicas elaboradas por $\mathrm{y}$ dentro del aparato burocrático de los Virreinatos para mantener la hegernonía española en América. "Es sobre todo por la via de la educación como los jesuitas se apropian rápidamente de la revolución gongorina y la convierten en un pesado instrumento pedagógico". explica Concha. "La memorización de largas tiradas de Góngora hacía que los alumnos coloniales, desde niños, se apartaran de sus circunstancias inmediatas para sumergirse, mediante el espejismo seductor de las palabras, en la distante patria metropolitana". ${ }^{22}$

Podemos concluir volviendo a la polémica actual sobre el valor de una práctica "neobarroca" en las letras latinoamericanas. Debe estar claro, que donde Sarduy propone un "barroco de revolución" modelado sobre los procedimientos lingüísticos del gongorismo sería más verosímil hablar, en el caso particular del gongorismo colonial, de un barroco de enmascaramiento, enajenación, represión. Por todo su esplendor, por todo su "vuelo atrevido" sintáctico-alusivo-metafórico, la dialéctica del gongorismo es una dialéctica paralizada. Bajo el pretexto de crear una nueva forma de trascendencia, su cultivo de la dificultad revela una vacuidad mecánica y ostentosa: un discurso frustrado y frustrante. Sarduy correctamente ve en esto la posiblidad de un "neobarroco del desequilibrio, reflejo estructural de un deseo que no puede alcanzar su objeto." 23 . Pero esto se debe a que el

22. Concha: "La literatura colonial", p. 46.

23. Sarduy: Barroco, p. 103. Sin embargo, hace falta notar que Sarduy no propone una simple identidad entre el barroco del siglo XVII y un neobarroco "de revolución":

... el barroco europeo y el primer barroco latinoamericano se dan como imágenes de un universo móvil y descentrado, pero aún armónico; se constituyen como portadores de una consonancia. . . Al contrario, el barroco actual, el neobarroco, refleja estructuralmente la inarmonía, la ruptura de la homogeneidad del logos en tanto que absoluto, la carencia que constituye nuestro fundamento epistémico. (pp.102-103) 
movimiento interno de la frase gongorina-ese desplazamiento continuo del significante que constituye su particular dificultad y placer-refleja una conciencia de clase contradictoria y perversa, incapaz de totalizar su relación con la historia. En la imaginación del barroco la posiblidad de sublimación no puede separarse de una conciencia agudizada de la imperfección y la mortalidad, creando así una oscilación perpetua entre monumentalización y entropía: el "vuelo atrevido" acaba en "desvanecimiento", la cornucopia revela el esqueleto constituido por su propia elaboración lingüística, la figura poética completada es una "tumba", la afinidad estética más profunda se siente no con el palacio, sino con la belleza mediatizada de la ruina, en donde la naturaleza ha "deshecho" una ilusión humana de poder y permanencia.

El gongorismo, indudablemente, compartió y comparte el signo de cierto tipo de radicalismo. Pero la "revolución poética" que significa se desarrolla en el siglo XVII precisamente en vez de y en contra de una revolución social del sistema estamental y colonial español. Como en el caso del puritanismo inglés, ésta tendría que elaborar, ante todo, un discurso accesible a lo que Blas de Otero llama "la inmensa mayoría"-el sujeto revolucionario. El gongorismo, por el contrario, produce deliberadamente una escritura que sólo puede ser manejada por una élite de estetas, letrados, arbitristas y funcionarios del aparato imperial-figuras que encuentran sus dobles en esos intelectuales burgueses antiburgueses(Flaubert, Baudelaire, Manet) que surgen después de las revoluciones de 1848. Representa, últimamente, una especie de narcisismo exacerbado y enlutado ante una forma de poder decadente. El estilo es una máscara, el duelo es "ese estado de conciencia en que el sentimiento trata de resucitar un mundo vacío en la forma de una máscara y deriva una satisfacción enigmática al contemplarla." 24

24. Benjamin: El origen de la tragedia alemana. 